\title{
Age-associated inflammation connects RAS-induced senescence to stem cell dysfunction and epidermal malignancy
}

\author{
L Golomb ${ }^{1}$, A Sagiv ${ }^{1}$, IS Pateras ${ }^{2}$, A Maly ${ }^{3}$, V Krizhanovsky ${ }^{1}$, VG Gorgoulis ${ }^{4,5,6,7}$, M Oren $^{*, 1}$ and A Ben-Yehuda ${ }^{\star, 3}$
}

Aging is the single biggest risk factor for malignant transformation. Among the most common age-associated malignancies are non-melanoma skin cancers, comprising the most common types of human cancer. Here we show that mutant $\mathrm{H}$-Ras activation in mouse epidermis, a frequent event in cutaneous squamous cell carcinoma (SCC), elicits a differential outcome in aged versus young mice. Whereas $\mathrm{H}$-Ras activation in the young skin results in hyperplasia that is mainly accompanied by rapid hair growth, $\mathrm{H}$-Ras activation in the aged skin results in more dysplasia and gradual progression to in situ SCC. Progression is associated with increased inflammation, pronounced accumulation of immune cells including $T$ cells, macrophages and mast cells as well as excessive cell senescence. We found not only an age-dependent increase in expression of several pro-inflammatory mediators, but also activation of a strong anti-inflammatory response involving enhanced IL4/L10 expression and immune skewing toward a Th2 response. In addition, we observed an age-dependent increase in the expression of Pdl1, encoding an immune suppressive ligand that promotes cancer immune evasion. Moreover, upon switching off oncogenic H-Ras activity, young but not aged skin regenerates successfully, suggesting a failure of the aged epidermal stem cells to repair damaged tissue. Our findings support an age-dependent link between accumulation of senescent cells, immune infiltration and cancer progression, which may contribute to the increased cancer risk associated with old age.

Cell Death and Differentiation (2015) 22, 1764-1774; doi:10.1038/cdd.2015.21; published online 20 March 2015

The convergence between aging and cancer harbors a unique dichotomy: whereas uncontrolled cell proliferation is one of cancer hallmarks, aging is associated with a gradual decay in tissue regeneration and overall compensatory proliferative capacity. Yet, aging remains the strongest single risk factor for cancer development. ${ }^{1,2}$ One example of an age-related cancer is cutaneous squamous cell carcinoma (SCC). ${ }^{3}$ SCC, the second most common skin cancer after basal cell carcinoma, commonly develops in sun-exposed skin and is prevalent in two main human groups, the elderly and organ transplant recipients. ${ }^{4}$ Both of these are paradigms of reduced immune competence, underscoring the role of the immune system in SCC biology. The immune system has a key role in eliminating incipient tumor cells, a process known as immune surveillance, ${ }^{5}$ demonstrated by the susceptibility of $\mathrm{Tcr}^{-/-}$mice, lacking $\gamma \delta \mathrm{T}$ cells, to DMBA/ TPA-induced skin cancer. ${ }^{6}$ As such, the gradual deterioration in immune response with advanced age, also known as immunosenescence, ${ }^{7}$ is one of several theories aiming to explain the convergence between aging and cancer. ${ }^{8,9}$ Adaptive immunity is considered to be more affected by aging than innate immunity, as reflected by the inability of old individuals to mount an effective humoral response. ${ }^{10}$ This is partially due to reduced lymphopoiesis, associated with events such as thymic involution ${ }^{11}$ and age-dependent skewing of hematopoietic stem cell commitment toward myeloid lineage differentiation. ${ }^{12,13}$ Age-dependent dysfunction of adaptive immunity can also result from intrinsic changes within different lymphocytic lineages. Senescence of immune cells was reported in both $\mathrm{CD}^{+}$and $\mathrm{CD}^{+}$lymphocytes, ${ }^{14,15}$ and is mainly characterized by loss of CD28 expression. ${ }^{16}$ This outcome is mostly associated with chronic exposure to viral infections like CMV or EBV, ${ }^{15}$ but exposure of normal $\mathrm{T}$ cells to cancer cells can also induce a senescence-like phenotype in T cells, characterized by loss of CD28 expression and upregulation of $\mathrm{p} 53, \mathrm{p} 21$ and $\mathrm{p} 16 .^{17}$

Although the immune system has an important role in preventing tumor growth, it can also promote cancer development and support tumor proliferation, invasion and metastasis. ${ }^{18}$ Several adverse conditions characterized by chronic inflammation, such as inflammatory bowel disease. ${ }^{19}$ and chronic liver inflammation ${ }^{20}$ are known risk factors for cancer development. In addition, dermal atrophy accompanied by chronic stromal inflammation, caused by

\footnotetext{
${ }^{1}$ Department of Molecular Cell Biology, Weizmann Institute of Science, Rehovot, Israel; ${ }^{2}$ Molecular Carcinogenesis Group, Department of Histology-Embryology, School of Medicine, University of Athens, Athens, Greece; ${ }^{3}$ Hadassah Medical School, The Hebrew University, Jerusalem, Israel; ${ }^{4}$ Department of Histology-Embryology, Medical School, National Kapodistrian University of Athens, 75 Mikras Asias Str., Goudi, 11527 Athens, Greece; ${ }^{5}$ Biomedical Research Foundation, Academy of Athens, 4 Soranou Efessiou, 11527 Athens, Greece; ${ }^{6}$ Faculty Institute for Cancer Sciences, University of Manchester, Manchester Academic Health Science Centre, Manchester M13 9WL, UK and ${ }^{7}$ Manchester Centre for Cellular Metabolism, University of Manchester, Manchester Academic Health Science Centre, Manchester M13 9WL, UK *Corresponding authors: M Oren and A Ben-Yehuda, Department of Molecular Cell Biology, Weizmann Institute of Science, POB26, 234 Herzl St., Rehovot 76100, Israel. Tel: +972 8934 2358; Fax: +972 8934 6004; E-mail: Moshe.oren@Weizmann.ac.il or Tel: +972 2677 6966; Fax: +972 2 677 7760; Email: benyehuda@ hadassah.org.il Abbreviations: SCC, squamous cell carcinoma; 4-OHT, 4-hydroxytamoxifen; OIS, oncogene-induced senescence; GSEA, gene set enrichment analysis; SA-beta-gal, senescence-associated beta galactosidase; $\mathrm{IHC}$, immunohistochemistry

Received 10.7.14; revised 14.1.15; accepted 03.2.15; Edited by G Melino; published online 20.3.15
} 
mesenchyme-dependent inhibition of Notch signaling, was found to be a driver for multifocal SCC development. ${ }^{21}$ In fact, chronic inflammation promoted by immune cells was recently recognized as one of the cancer hallmarks. ${ }^{22}$ Increased inflammation can occur in a variety of normalaged tissues, a phenomenon dubbed inflammaging. ${ }^{23}$ This is partly attributed to accumulating senescent cells, observed in aged tissues. ${ }^{24}$ Such cells secrete a plethora of pro-inflammatory molecules, in a process termed senescence-associated secretory phenotype (SASP). ${ }^{25}$ This is believed to promote age-related diseases as well as support malignant growth. ${ }^{24}$ Age-related inflammation is also believed to contribute to the dwindling regenerative capacity of aged adult stem cells. ${ }^{12,26}$ SCC can originate in hair follicle stem cells (HF-SC), ${ }^{27}$ raising the question whether inflammation can promote the neoplastic transformation of these adult epidermal stem cells.
Here we describe the use of a transgenic mouse strain expressing activated mutant $\mathrm{H}$-Ras in the epidermis to elucidate the differential response of young versus aged animals to such oncogenic trigger.

\section{Results}

Differential response of aged skin to H-Ras overexpression. To investigate age-dependent tissue response to oncogenic RAS activation, we utilized mice expressing a conditional ER: H-Ras ${ }^{\mathrm{G} 12 \mathrm{~V}}$ transgene under regulation of the $\mathrm{K} 14$ promoter. $^{28}$ In these mice, oncogenic $\mathrm{H}$-Ras activity in keratinocytes is regulated reversibly by 4-hydroxytamoxifen (4-OHT). We compared 2-4-month-old mice (young) to 18-22-month-old mice (old). 4-OHT, or ethanol (EtOH) as control, was applied daily on the shaved back skin of the mice. After 1 month of treatment, massive changes were

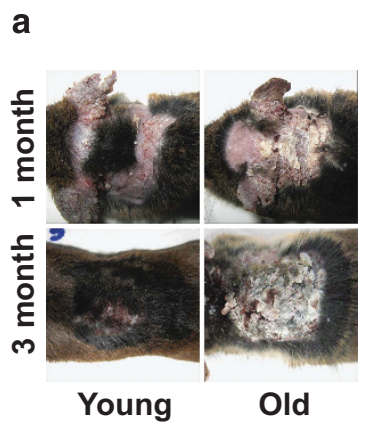

C

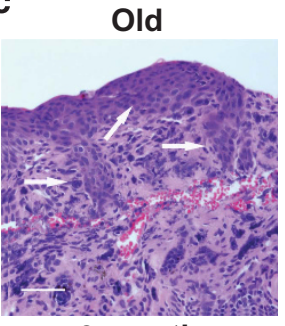

3 month

b

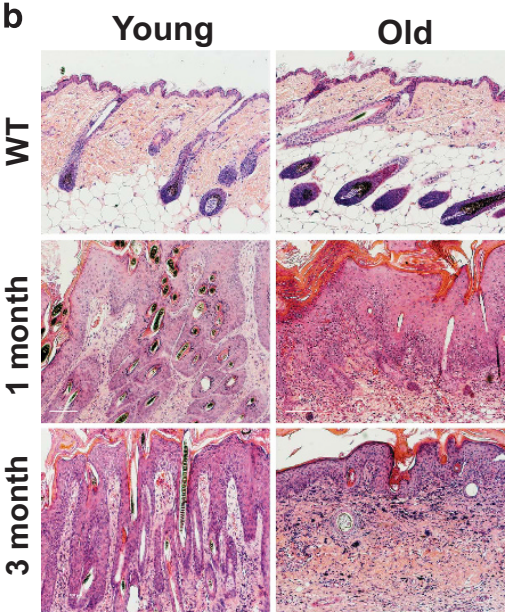

e

Hummerich skin cance progression

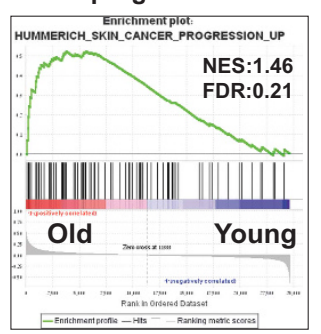

d

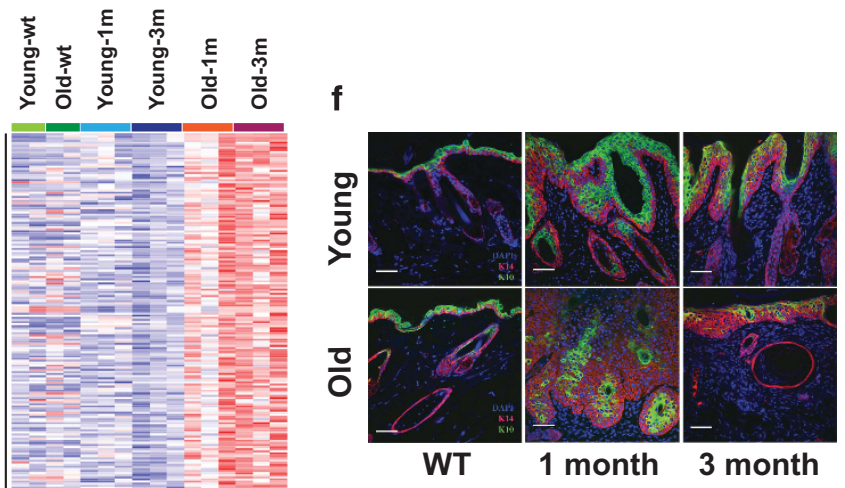

Figure 1 Conditional H-Ras activation in the skin of old but not young mice results in in situ SCC. 4-OHT was applied on the shaved back skin of both wt and transgenic mice for the duration of either 1 or 3 months. (a) Representative picture of young and old transgenic mice following 1 and 3 month of $\mathrm{H}$-Ras activation. For the 1 month procedure, a total of 10 mice in two independent experiments were examined. For the 3-month procedure, a total of 14 mice in three independent experiments were examined. (b) H\&E staining of sections of the back skin of young and old control wild-type mice (WT, upper) or H-Ras transgenic mice after 1 or 3 months of 4-OHT treatment. (c) Representative image of in situ SCC in 3-month-treated-old mice. White arrows indicate full thickness atypia and focal area of invasion. Scale bar $=50 \mu \mathrm{m}$. (d) RNA was extracted from whole skin (epidermis + dermis) and subjected to expression array analysis. Heat map of differential gene expression between WTand $\mathrm{H}$-Ras transgenic young $(\mathrm{Y})$ and old $(\mathrm{O})$ mice, treated with 4-OHT for 1 or 3 months, Fold change $>1.5, P$-value (permutation test) $<0.05$. (e) GSEA plot depicting SCC progression-related genes (MSigDB C2 CGP) ${ }^{31}$ in old versus young H-Ras activated mice. (f) Representative immunofluorescence images of back skin sections of WT and H-Ras-transgenic young and old mice treated with 4-OHT for 1 or 3 months, stained with DAPI (blue) and antibodies against K10 (green) and K14 (red). Scale bar $=50 \mu \mathrm{m}$. (g) qRT-PCR analysis of $K 10$ and $K 14$ mRNA, amplified from whole skin RNA of the indicated mice. Values represent relative expression normalized to Gapdh mRNA \pm SEM; $n=3$ for WT and $n=5,6,4$ and 6 , respectively, for H-Ras activated mice. ${ }^{* *} P<0.01$ (Student's $t$-test) 
observed in the 4-OHT-treated skin in both age groups (Figure 1a). In the young mice, rapid hair regrowth was observed as early as 10-14 days from the onset of 4-OHT treatment, yet the skin patches of the old mice remained hairless (Figure 1a). Histolgical examination revealed markedly acanthotic epidermis together with hyperparakeratosis in both young and old skin. Notably, at variance with young mice, the skin of old mice displayed mild-to-moderate dysplasia; furthermore, extensive inflammation was seen in the old skin when compared with that of young mice (Figure 1b, middle panel). However, no carcinoma was detected in either age group. We therefore prolonged $\mathrm{H}$-Ras activation to 3 months. Owing to the relatively high mortality of old mice under the 1 month protocol (data not shown), the volume of administrated 4-OHT was reduced to cover only a smaller patch of skin. The prolonged H-Ras activation revealed pronounced differences between the response of old and young mice. Whereas excessive hair growth was evident in all young mice, no hair regrowth was seen in the old animals. Importantly, development of in situ SCC could now be observed in about half of the old mice, but in none of the young animals (Figures $1 \mathrm{~b}$ and $\mathrm{c}$, white arrows). To determine whether higher levels and/or activity of $\mathrm{H}$-Ras in the old skin might account for the observed differences, we assessed $\mathrm{H}$-Ras activity by IHC staining for phosphorylated ERK ( $p-E R K)$. No significant differences were discernible between young and old mice who were treated with 4-OHT for 3 months (Supplementary Figure S1A). In both cases, p-ERK staining was almost exclusively confined to the epidermis (Supplementary Figure S1B), providing further evidence for epidermal-specific $\mathrm{H}$-Ras activation.

To explore the underlying molecular processes, RNA from corresponding skin samples as well as from young and old non-transgenic control mice was subjected to expression array analysis. To identify genes expressed differentially between young and old H-Ras-activated mice, we used the Gene-E comparative marker selection tool (The Broad Institute: https://www.broadinstitute.org/cancer/software/GENE-E/). We compared the young versus old group, each comprising both the 1- and the 3-month 4-OHT samples together. We selected genes differentially expressed with $P<0.05$ and fold change above 1.5. Four hundred and sixty genes were deemed differentially expressed between treated young and old mice (Figure 1d). Of those, 395 were upregulated in old skin. Gene set enrichment analysis (GSEA) ${ }^{29,30}$ revealed upregulation in the old skin of a gene set previously described in cutaneous SCC progression (Figure 1e), ${ }^{31}$ lending further support to the conclusion that, in this experimental model, prolonged oncogene activation can progress to a malignant state in old but not young skin.

One trait of high-grade skin dysplasia and SCC is loss of proper skin stratification, which can be visualized by staining of different epidermal layers. To explore a possible differentiation defect, we used two markers of keratinocyte differentiation: keratin 14 (K14), expressed in the basal layer of the epidermis, and keratin 10 (K10), which marks the suprabasal layer (Figure 1f, left). After 1 month of $\mathrm{H}$-Ras activation, overall levels of $\mathrm{K} 14$ and $\mathrm{K} 10$ were relatively similar in both young and old mice (Figure 1f, middle). Yet, when 4-OHT treatment was extended to 3 months, old mice displayed a significantly higher
$\mathrm{K} 14 / \mathrm{K} 10$ ratio relative to the young animals. This included also patches of epidermis lacking almost completely K10 staining, suggestive of full thickness atypia commonly observed in in situ SCC (Figure 1f, right). In agreement, K14 mRNA was elevated by $\mathrm{H}$-Ras activation in both age groups at both time points (Figure 1g), as expected from the observed expansion and thickening of the basal epidermal layer. Surprisingly, although $\mathrm{K} 10 \mathrm{mRNA}$ was strongly reduced in both age groups after 1 month of treatment (Figure 1g), it recovered by 3 months in the young skin but remained low in the old skin (Figure 1g). Together, these observations suggest that old mice manifest a differentiation defect reminiscent of neoplastic growth.

Oncogene-induced cellular senescence (OIS) is believed to be an important tumor suppressor mechanism. ${ }^{32,33}$ However, cellular senescence is a double-edged sword, which can also promote tumorigenesis through induction of inflammatory factors. $^{34}$ RAS activation can evoke OIS in cultured keratinocytes ${ }^{35}$ but little is known about this process in vivo. In apparent agreement with the ability of activated RAS to drive OIS, staining for the senescence marker senescenceassociated beta galactosidase (SA-beta-gal) confirmed relatively high levels of senescent cells in the skin of 4-OHTtreated transgenic mice (Figure 2a). Surprisingly, the staining was predominantly in the dermis and not in keratinocytes, harboring activated $\mathrm{H}$-Ras. Although dermal SA-beta-gal positive cells were detected in both age groups, they were approximately twofold more abundant in the old skin in both 1month and 3-month treatments (Figure 2b). mRNA levels of $p 16 / C d k n 2 a$, a CDK inhibitor that enforces senescence via the $\mathrm{pRb}$ pathway, were significantly higher in the old mice at both time points (Figure 2c). In agreement, p16 protein levels (determined by $\mathrm{IHC}$ ) were significantly higher in the dermis of old mice treated for 3 months (Figure 2d and Supplementary Figure S2A), as was also the case for nuclear staining of p21, another cell cycle inhibitor (Figure $2 \mathrm{~d}$ and Supplementary Figure S2B). Thus, senescent cells accumulate more readily in the stromal compartment of the old skin as a consequence of oncogenic $\mathrm{H}$-Ras activation in the epidermis.

GSEA analysis of mRNA expression data (see Figure 1d) confirmed enrichment for SASP genes in old skin (Figure 2e), based on a previously described set of proteins secreted by cultured human senescent cells. ${ }^{36,37}$ Expression of four SASP genes, CCR1, SPP1, IL6 and IL1 3 , was also validated by reverse transcriptase quantitative real-time PCR (qRT-PCR) (Figure 2f). Expression of all four genes was elevated in both age groups after 1-month treatment, and was only marginally higher in the old group. However, after 3 months of treatment, the old mice displayed significantly higher levels of those mRNAs than the young animals. Of note, IL6 is known to promote tumorigenesis in many settings. It is thus conceivable that the augmented pro-inflammatory pattern may promote the progression of pre-malignant lesions toward cancer in aged animals.

IL4/IL10 pathway activation in aged skin upon H-Ras induction. $\mathrm{H}$-Ras activation elicited a marked accumulation of immune cells in the skin already after 1 month of treatment and more so after 3 months, as evidenced by CD45 immunostaining (Figure 3a). Notably, this accumulation was substantially greater in old skin. Furthermore, GSEA analysis 


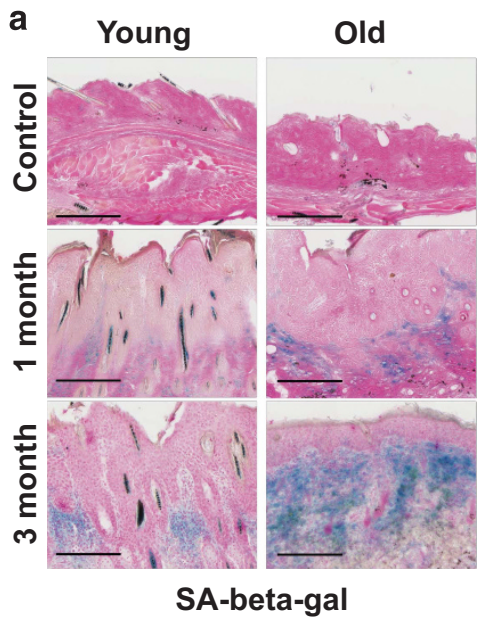

C

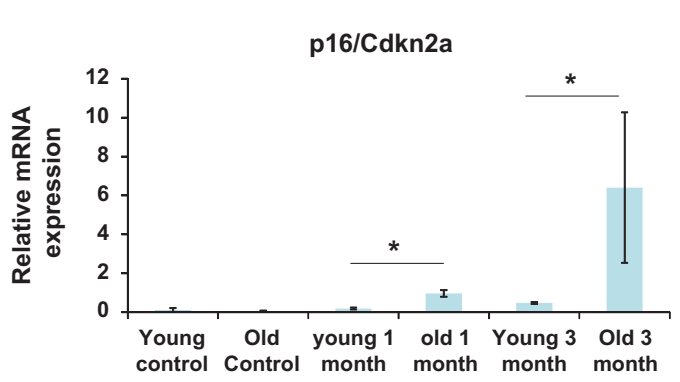

e

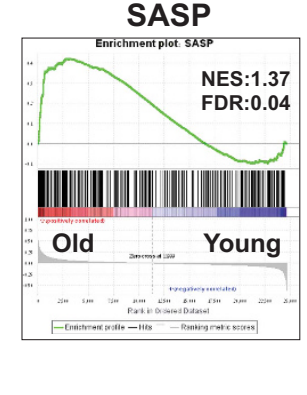

b

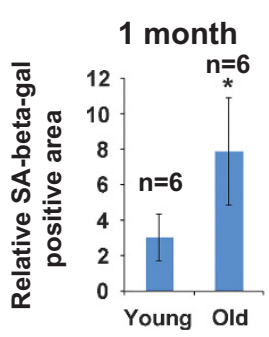

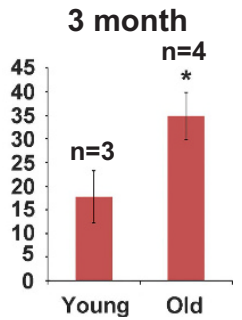

Young Old
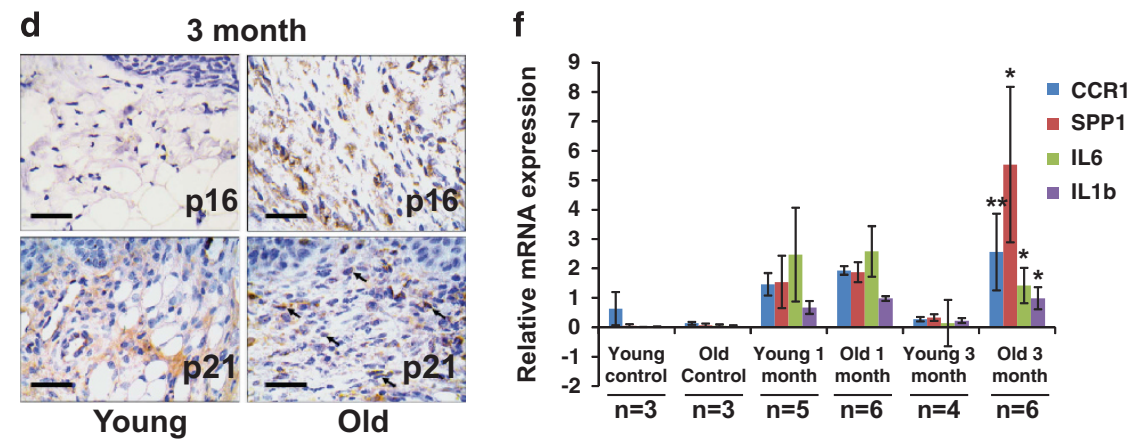

Figure 2 Age-dependent accumulation of senescent cells following H-Ras activation. (a) SA-beta-gal staining (blue) identifies senescent cells in the back skin of young and old WT or H-Ras transgenic mice after 1 or 3 months of 4-OHT treatment. Scale bar $=200 \mu \mathrm{m}$. (b) Quantification of SA-beta-gal staining done with ImageJ $(\mathrm{NIH})$. Values $=$ mean of SA-beta-gal positive area divided by total sample area \pm SD. ${ }^{*} P<0.05 . n=$ number of mice. (c) qRT-PCR analysis of $p 16 / C d k n 2 a$ mRNA performed on total skin RNA values represent relative expression normalized to Gapdh mRNA \pm SEM; $n=3$ for WT and $n=5,6,6$, respectively, for H-Ras activated samples. ${ }^{*} P<0.05$. (d) Representative IHC images of p16 (upper) and p21 (lower). Arrows indicate nuclei with varying degrees of positive p21 staining. Scale bar $=50 \mu \mathrm{m}$. (e) GSEA plot depicting enrichment for SASPrelated signature in H-Ras-activated mice. SASP gene set adopted from. ${ }^{25,37}$ (f) qRT-PCR analysis of CCR1, SPP1, IL6 and IL $1 \beta$ mRNA in total skin RNA. Values represent relative expression normalized to Gapdh mRNA \pm SEM. $n=$ number of mice in each group. ${ }^{*} P<0.05$

identified many of the genes upregulated in H-Ras-activated old mice as immune related (Figures $3 b-d$ ). Moreover, old skin displayed pronounced TLR signaling and NF- $k \mathrm{~B}$ signatures, both implicated in inflammation-driven cancer progression. ${ }^{38,39}$ Indeed, the old $\mathrm{H}$-Ras-challenged skin was markedly enriched for $\mathrm{T}$ cells (CD3+, Figure $3 e$ ) and macrophages (Figure $3 \mathrm{f}$ ). NF- $k \mathrm{~B}$ is a master regulator of inflammation, whose role in driving tumorigenesis through chronic inflammation is well established. ${ }^{19}$ To determine whether NF- $\kappa \mathrm{B}$ might be involved in the inflammatory response observed in the $\mathrm{H}$-Ras-activated skin, we performed IHC for the NF- $k B$ subunit $p 65$. As seen in Figure $4 a$ and Supplementary Figure S3A, elevated levels of nuclear p65 were present in the old skin relative to young skin, indicating augmented NF- $\kappa \mathrm{B}$ activation. Interestingly, NF- $\kappa \mathrm{B}$ activation was observed in both epidermis and dermis, implying that both epithelial and stromal/immune cells participate in the inflammatory response. Further analysis of the inflammatory response in old skin revealed strong activation of the IL4 and IL10 pathways, both associated with Th2-type immunity (Figures $4 b-d$ ). The old mice also displayed elevated expression of IL10 (Figure 4c, middle panel) and TNFa (Figure 4e), both implicated in the Th2 response. ${ }^{40,41}$
In contrast, young skin displayed elevated expression of IL20 and several members of the IL20 family, for example, IL19 and IL24, while others like IL22 were not significantly changed (Figure 4c, lower panel, and Figure 4d). IL4 activity in the skin can elicit a Th2 immune response and inhibit epidermal differentiation via STAT6. ${ }^{42,43}$ Indeed, we observed increased expression of JAK/STAT pathway genes in the treated old mice, including a prominent increase in Jak3 mRNA (Supplementary Figures S3B and C).

Recruitment of several types of Th2-related innate immunity cells such as macrophages, mast cells and eosinophils can contribute to tumor development and progression. ${ }^{44}$ GSEA analysis confirmed a Th2 expression signature in the old mice (Figure $5 \mathrm{a}$ ) based on a gene signature identified by Bosco et al. $^{45}$ in allergen-induced Th2 cell response implicated in human atopic disease. Furthermore, moderately elevated numbers of CD206-positive cells, indicative of M2-polarized macrophages, ${ }^{46}$ were observed in the dermis and hypodermis of $\mathrm{H}$-Ras-driven skin lesions of the old mice at the 3-month treatment (Figure 5b). Remarkably, pronounced accumulation of mast cells (Toluidine blue positive) was seen in the 3-month treated old skin but to a much lesser extent in young skin (Figure 5c). The augmented presence of mast cells in the aged 
a

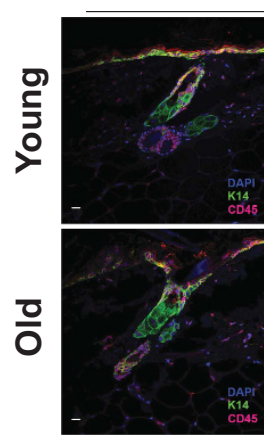

WT
CD45

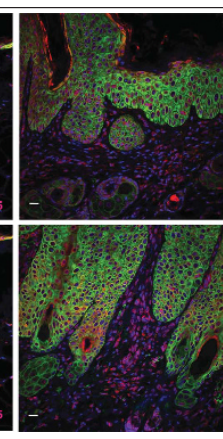

1 month

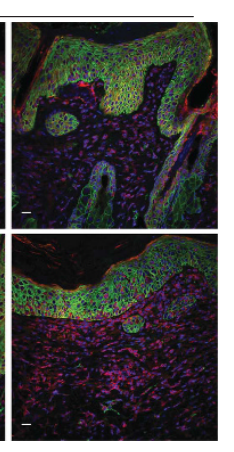

3 month b

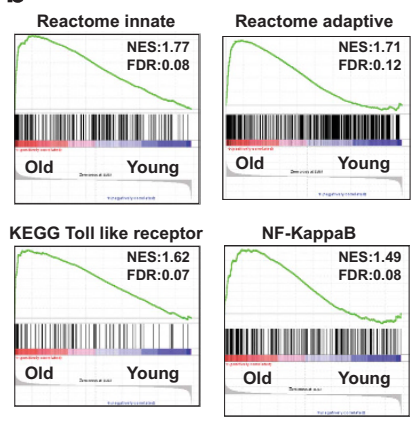

c

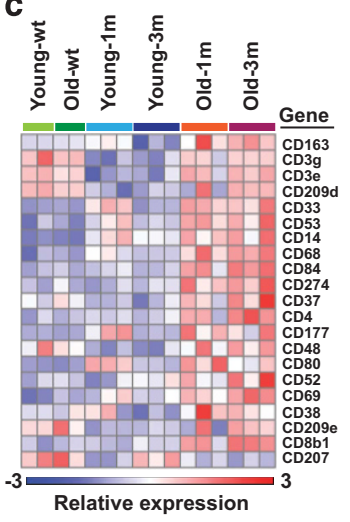

d

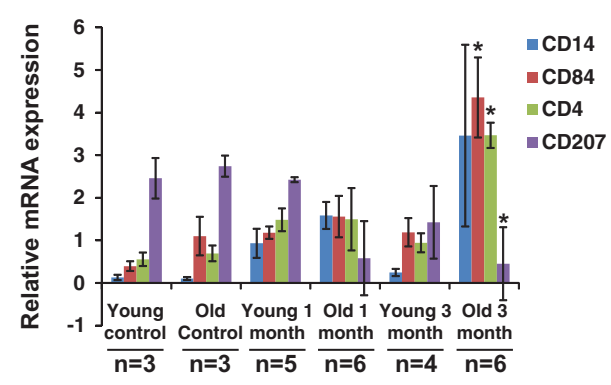

e

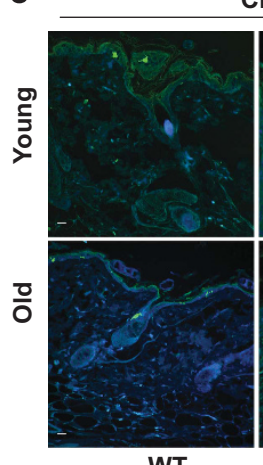

CD3

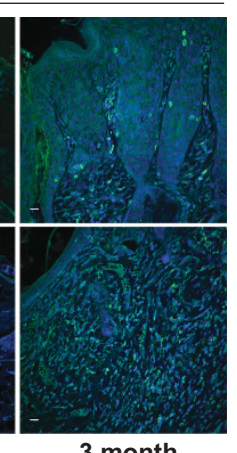

f

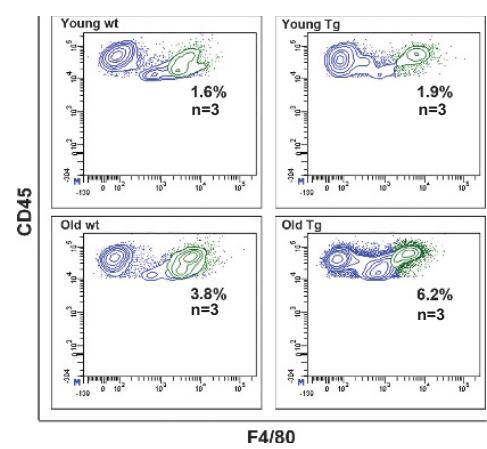

Figure 3 Excessive inflammation in aged skin in response to epidermal $\mathrm{H}$-Ras activation. (a) Immunofluorescence staining as in Figure 1e, except that sections were stained for DAPI (blue), K14 (green) and CD45 (red). Scale bar $=50 \mu \mathrm{m}$. (b) GSEA plot of immune activity in young and old H-Ras-activated mice (MSigDB C2 CP: Reactome, C2 CP: KEGG, C3:TFT). (c) Heat map depicting the differential expression of immune surface markers between WT- and H-Ras-activated young and old mice, fold change $>1.5$, $P$-value (permutation test) $<0.05$. (d) qRT-PCR analysis of CD14, CD84, CD4 and CD207 mRNA in total skin RNA. Values represent relative expression normalized to Gapdh mRNA \pm SEM. $n=$ number of mice in each group. ${ }^{*} P<0.05$. (e) Immunofluorescence staining as in Figure 1e, except that sections were stained for DAPI (blue) and CD3 (green). Scale bar $=50 \mu \mathrm{m}$. (f) Representative FACS analysis of F4/80-positive macrophages extracted from the skin of WT (left) and 3-month 4-OHT-treated transgenic (right) young and old mice. Numbers represent the mean percentage of F4/80-positive cells out of the total CD45-positive cells. $n=3$

tissue was also reflected by increased expression of MCPT2, encoding a mast cell-specific protease (Figure 5d); the difference between young and old mice was particularly accentuated after prolonged $\mathrm{H}$-Ras activation (Figure $5 \mathrm{~d}$ ). The IL4/L10 Th2 immune response is suppressive in essence. Although probably mounted to dampen the pro-inflammatory response instigated by oncogene activation in the keratinocytes, it can eventually inflict tissue damage by recruiting ECM modulators such as mast cells and eosinophils. Importantly, the Th2 response can also modulate immune evasion of malignant cells. In particular, CD274/Pdl1, encoding the PDL1 ligand of the PD1 T cell receptor, can suppress the immune recognition and elimination of numerous types of cancer cells, ${ }^{47}$ including SCC. ${ }^{48}$ Remarkably, expression of CD274/ $P d l 1$ was elevated in old skin after $\mathrm{H}$-Ras activation (Figure 3c, Figures $5 \mathrm{e}$ and $\mathrm{f}$ and Supplementary Figure S4). This raises the intriguing possibility that augmented immune evasion and suppression of $\mathrm{T}$ cell-mediated tumor cell elimination facilitate age-related cancer progression.

The regenerative capacity of old tissues is often compromised. To determine whether this was also true for recovery from oncogene-induced tissue damage, 4-OHT-treated mice were either killed immediately after 4 weeks of $4-\mathrm{OHT}$ treatment (4 weeks) or allowed to recover for an additional 2 weeks without further 4-OHT treatment ( 6 weeks). Although young mice showed fast recovery of the skin, including rapid hair regrowth and disappearance of most of the cutaneous aberrations (Figure 6a), regeneration was markedly delayed in old mice. In addition, most of the treated skin remained hairless in the aged mice, suggesting stem cell dysfunction. Histologically, there is almost complete reversal of the skin hyperplasia and hyperkeratosis in the young mice, whereas the aged epithelium remained hyperplastic and inflamed (Figure 6b). After 2 weeks of recovery, numerous Ki67positive proliferating cells were still evident in both age groups, but were significantly more abundant in the aged, hyperplastic skin (Figure 6c and Supplementary Figure S5A, 6 weeks). Thus, old skin is severely defective in its ability to restore normal tissue homeostasis upon termination of oncogeneinduced signaling. The persistent hyperplasia is also reflected by increased accumulation of nuclear $p$-ERK in the old mice after 4-OHT withdrawal (Supplementary Figure S5B, 6 weeks). The elevated $p$-ERK signal is evident in the upper layers of the epidermis, suggesting that it is not due to residual K14:H-Ras 


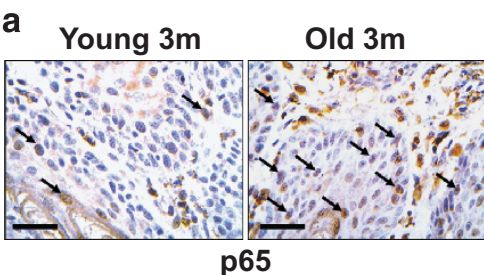

\section{b Lu IL4 signaling}

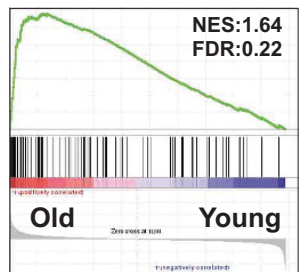

Biocarta IL10 pathway

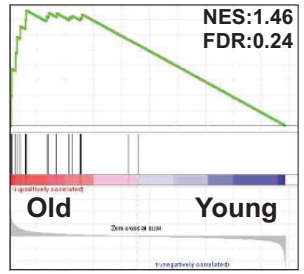

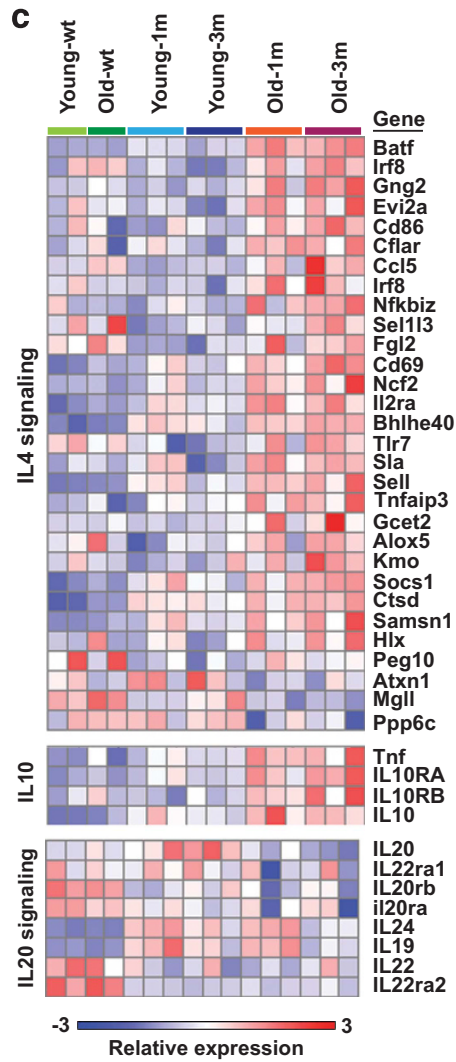

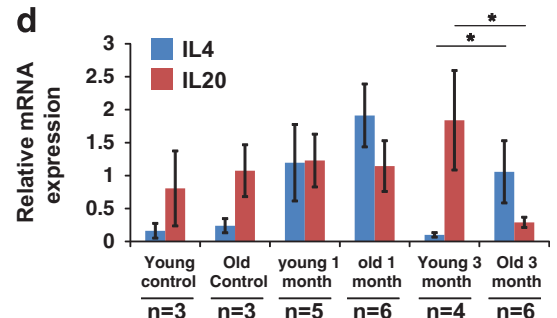

e

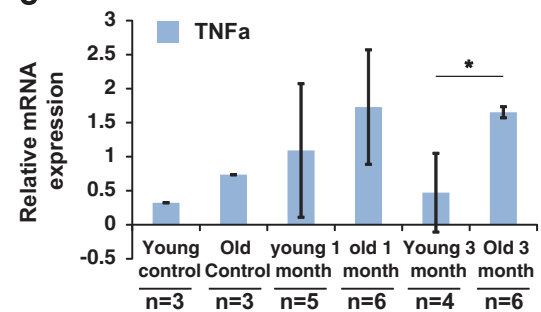

Figure 4 Increased activation of the IL4/L10 pathway in old skin. (a) Representative IHC images of p65 staining. Arrows indicate nuclear p65 staining. Scale bar $=50 \mu \mathrm{m}$. (b) GSEA plot of IL4/LL10-related signature in young and old H-Ras-activated mice (MSigDB C2 CGP: Lu IL4 signaling, C2 CP:Biocarta IL10). (c) Heat map of differential expression of genes related to the IL4/LL10/IL20 pathways in WT- and H-Ras-activated young and old mice. (d, e) qRT-PCR analysis of IL4, IL20 (d) and TNF $\alpha$ (e) mRNA in total skin RNA. Values represent relative expression normalized to Gapdh mRNA \pm SEM. $n=$ number of mice in each group. ${ }^{*} P<0.05$ (e)

activity, which is expected to be exerted primarily in the lower, basal layer of the epidermis.

Persistent senescent cells may promote tumor growth and tissue dysfunction. This is presumably why prompt clearance of such cells by the immune system is essential for proper tissue regeneration. ${ }^{49}$ Of note, persistence of senescent cells in immune compromised mice was shown to promote cancer development. ${ }^{50}$ SA-beta-gal analysis (Figure $6 \mathrm{~d}$ ) revealed that whereas dermal senescent cells were hardly detectable in young skin after 2 weeks of recovery, many still persisted at that time in the old mice. Although we cannot exclude the possibility that given a longer recovery period the old mice may eventually achieve full tissue recovery and clearance of senescent cells, our observation suggests that old animals might have a compromised ability to clear senescent cells from their tissues, accompanied by delayed tissue recovery.

The results in Figure 6 suggest that old mice have a defect in skin regeneration after reversible $\mathrm{H}$-Ras activation. Analysis of the expression array data (see Figure 1d) revealed that the major driver of variance in gene expression in this experimental model was H-Ras, accounting for 4046 genes differentially expressed between WT and induced transgenic skin regardless of age (Figure 7a). Of those, 2338 genes were downregulated upon $\mathrm{H}$-Ras activation, whereas 1707 others were upregulated. HF-SCs are pivotal in skin regeneration upon wound healing; of note, improper wound healing promotes SCC development. To explore possible effects of $\mathrm{H}$-Ras activation on HF-SCs, we compared the H-Ras up- and downregulated genes to a previously described HF-SC signature. ${ }^{51}$ Remarkably, almost $20 \%$ of the H-Ras downregulated genes overlapped with the HF-SC signature (Figure 7b, upper left). Of particular note, many of those (197 genes) are characteristic of quiescent HF-SC (qHFSC, Figure $7 b$ ), whereas only a significantly smaller number ${ }^{46}$ corresponds to active HF-SC (aHF-SC). Moreover, the H-Ras upregulated genes display extensive overlap with transit amplifying signature genes (HF-TAC; Figure 7b, lower right), which is not the case for the H-Ras downregulated genes (Figure 7b, lower left). This effect was also validated by RTqPCR for representative genes, including USP18, TLE4, FGF18, LYPD6, NPNT, LHX2 as well as KRT15, whose expression in the skin were strongly downregulated following $\mathrm{H}$-Ras activation for 1 month in both young and old mice (Figure 7c). We further evaluated the HF-SC status following $\mathrm{H}$-Ras activation by staining for two HF-SC markers, keratin 15 (K15) and CD34. ${ }^{52}$ Staining was performed on skin from mice treated for 4 weeks with 4-OHT, followed by 2 weeks of 4-OHT withdrawal (6 weeks). Consistent with the expression 
a

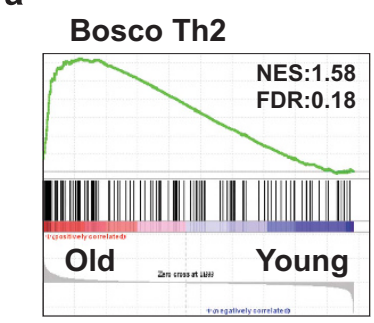

b

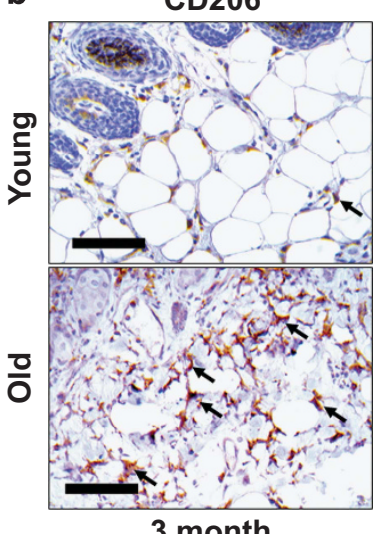

c

을

d

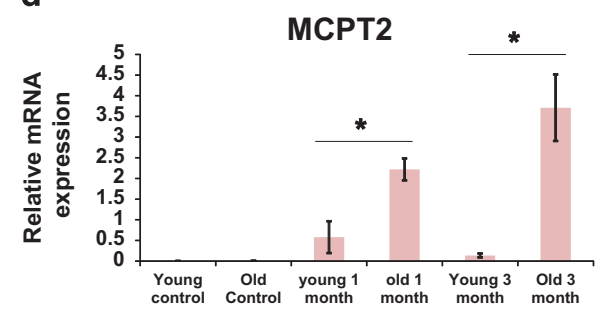

Toluidine blue

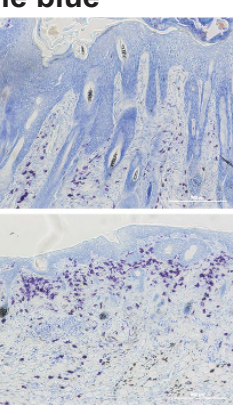

3 month e

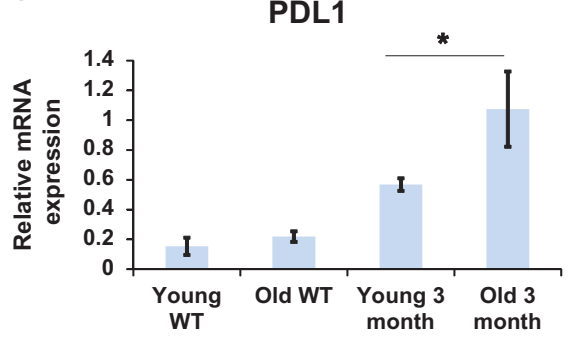

f

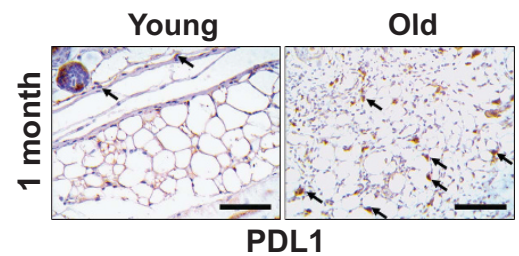

Figure 5 Immune activity in old skin is skewed towards a Th2 response. (a) GSEA plot of Th2-related signature in young and old H-Ras-activated mice (MSigDB C2 CGP: Bosco allergen-induced Th2-associated module). (b) Representative IHC images of CD206 staining. Arrows indicate positive cells. Scale bar $=100 \mu \mathrm{m}$. (c) Toluidine blue staining of back skin sections of WT- and 3-month 4-OHT-treated H-Ras transgenic young and old mice. Scale bar $=100 \mu \mathrm{m}$. (d) qRT-PCR analysis of MCPT2. Values represent relative expression normalized to Gapdh mRNA $\pm \mathrm{SD} ; n=3$ for WT and $n=4$ for H-Ras-activated samples. ${ }^{*} P<0.05$. (e) qRT-PCR analysis of $P D L 1$. Values represent relative expression normalized to Gapdh mRNA $\pm \mathrm{SD} ; n=3$ for WTand $n=15,14$, respectively, for H-Ras-activated samples. ${ }^{*} P<0.05$. (f) Representative IHC images of PDL1 staining (arrows). Scale bar $=50 \mu \mathrm{m}$

array results, a marked decrease in K15/CD34-positive cells was observed after 4 weeks of 4-OHT treatment in both age groups (Figure $7 \mathrm{~d}$, compare upper panels to middle panel). Remarkably, after 2 weeks of 4-OHT withdrawal, young but not old mice showed considerable numbers of K15/CD34-positive cells (Figure $7 d$, lower panel). Together, these data suggest that $\mathrm{H}$-Ras activation in the basal epidermis possibly drives HF-SCs differentiation into HF-TAC. Surprisingly, expression of HF-SC-associated genes was markedly recovered by 3 months of $\mathrm{H}$-Ras activation in the skin of young mice (Figure 7c), as observed also after 4-OHT withdrawal (Figure 7d). However, this did not happen in the old mice. Thus, while HF-SC recovery and homeostasis is achieved in young mice, the old animals fail to do so, likely underpinning their defect in skin regeneration.

\section{Discussion}

Despite its central role in SCC development, ${ }^{53}$ activation of $\mathrm{H}$-Ras alone is insufficient to induce invasive carcinoma. ${ }^{54}$ Although other genetic lesions such as p53 mutations are also common in malignant SCC, they are also found in benign lesions that can remain dormant for many years before they develop into SCC. ${ }^{55}$ This raises the question how cells harboring mutations in key oncogenes and tumor suppressors can remain in a state of dormancy for many years, progressing to cancerous growth only at old age. Here we show that conditional activation of oncogenic $\mathrm{H}$-Ras in the epidermis of aged mice results in in situ SCC resembling human Bowen's disease, an established precursor of invasive SCC. ${ }^{56}$ In contrast, the outcome of similar $\mathrm{H}$-Ras activity in young skin results in benign hyperproliferation accompanied by excessive hair growth. We believe that this model better recapitulates the human condition, as most human invasive SCC progress from either actinic keratosis or bowenoid lesions, considered in situ or early $\mathrm{SCC}^{56}$ and $\mathrm{H}$-Ras mutations can already be found in those lesions. ${ }^{57}$ The pronounced age-dependent differences in neoplastic phenotype are seen in correlation with the level and type of inflammation emerging in the young versus old skin. Compared with control skin, both age groups display elevated involvement of both innate and adaptive immunity. However, the immune response in the old skin is far more extensive. Among the most conspicuous phenotypes seen in the $\mathrm{H}$-Ras-activated old skin is increased infiltration of both $\mathrm{T}$ and B lymphocytes. B-cells can promote SCC development by enabling recruitment of innate immune cells. ${ }^{58}$ Furthermore, epidermal activation of $\mathrm{c}$-Fos promotes $\mathrm{CD}^{+}{ }^{+} \mathrm{T}$-cells recruitment that drives epidermal hyperplasia, ${ }^{59}$ which when combined with a single DMBA treatment gives rise to extremely aggressive tumors. ${ }^{59}$ Moreover, cutaneous infiltration of chronic lymphocytic leukemia predisposes to SCC development, ${ }^{60}$ although $\mathrm{CD}^{+}$and $\mathrm{CD}^{+} \mathrm{T}$ cells can also 
a

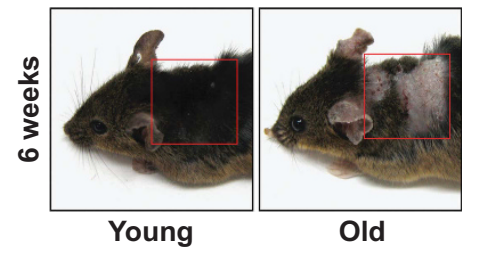

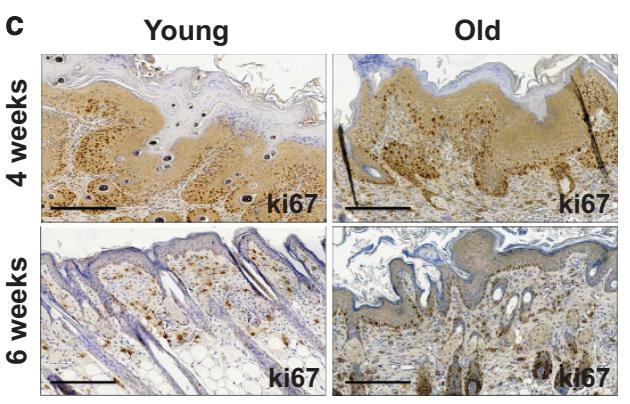

d

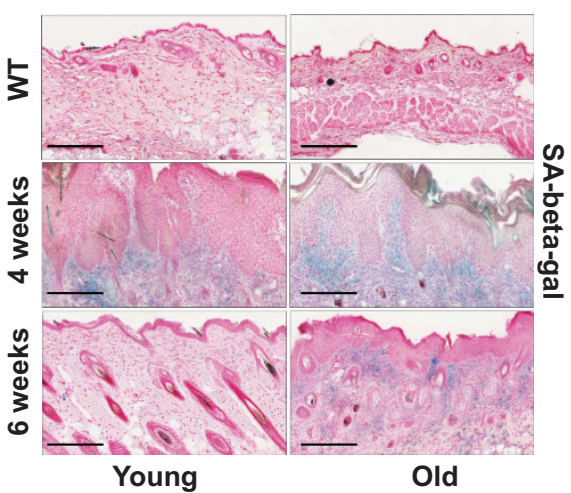

Figure 6 Persistence of senescent cells in aged skin. (a) Representative pictures of young and old transgenic mice 2 weeks after 1 month of 4-OHT treatment followed by 2 weeks of recovery without 4-OHT. Red square marks the region where 4-OHT was applied. (b) H\&E staining of sections of the back skin of young and old transgenic mice treated as in (a) and killed either before (4 weeks) or after ( 6 weeks) 2 weeks of recovery without $4-\mathrm{OHT}$. Scale bar $=500 \mu \mathrm{m}$. (c) Ki67 immunohistochemistry staining of sections prepared as in (b). Scale bar $=200 \mu \mathrm{m}$. (d) SA-beta-gal staining (blue) of sections from mice treated as in $\mathbf{b}$. Scale bar $=200 \mu \mathrm{m}$

confer protection against SCC in Notch-deficient mice. ${ }^{61}$ Remarkably, even though adaptive immunity is markedly attenuated in old age, we observe massive recruitment of lymphocytes to the old skin following $\mathrm{H}$-Ras activation. The immune response in the old skin is skewed toward a Th2suppressive mode, including elevated levels of IL10 and IL4 and accumulation of mast cells. ${ }^{62}$ Following TCR activation in aged mice, naive $\mathrm{CD} 4^{+} \mathrm{T}$ cells differentiate toward a Th2 fate. ${ }^{63}$ Chronic Th2 inflammation is pernicious, as it recruits mast cells and eosinophils, both ECM modulators that can mediate tissue destruction and support tumor growth, ${ }^{64,65}$ although in c-Kit ${ }^{-1-}$ mice mast cells can actually confer tumor protection. ${ }^{66}$ In addition to mast cells and eosinophils, M2-polarized macrophages commonly found in the tumor microenvironment are well documented for their ability to support tumor growth. ${ }^{67}$

Surprisingly, H-Ras activation in the mouse epidermis resulted in massive accumulation of senescent cells in the dermis rather than in the epidermis. It has been proposed that differentiation, not senescence, is the preferred tumor suppressive mechanism in keratinocytes. ${ }^{68}$ This might explain why very little senescence is observed in the epidermis upon $\mathrm{H}$-Ras activation. In contrast, the massive accumulation of senescent cells in the dermis and particularly in the old skin suggests that, following immune recruitment, infiltrating immune cells, possibly lymphocytes, undergo senescence. The rapid clearance of the senescent cells from the skin after termination of $\mathrm{H}$-Ras activity favors the notion that these are indeed immune cells such as lymphocytes, as senescent epidermal cells were reported to linger in the skin for significantly longer periods. ${ }^{69}$ Senescence of T cells, namely $\mathrm{CD}^{+} / \mathrm{CD} 8^{+} \mathrm{CD} 28^{-}$, is attributed to adaptive immune dysfunction during aging. ${ }^{70}$ Accumulation of $\mathrm{CD} 8^{+} \mathrm{CD} 28^{-} \mathrm{T}$ cells is also quite common in different human cancers, such as lung ${ }^{71}$ and colorectal. ${ }^{72}$ Conceivably, infiltrating $T$ cells undergo exhaustion more rapidly in the old skin and so contribute to malignant growth directly via secretion of pro-inflammatory cytokines $^{73}$ or indirectly by retarding the appropriate immune response to the growing tumor. ${ }^{17}$ Moreover, the fact that many senescent cells persist in the old skin even 2 weeks after termination of $\mathrm{H}$-Ras activity might suggest that in aging tissue senescent cells are fast to accumulate but slow to be eliminated, contributing to aging-related pathologies and cancer development. The immune system has a crucial role in clearing senescent cells from damaged tissue.$^{50,74}$ Hence, the diminished competence of the immune system in the aged might be responsible for the accumulation and persistence of senescent cells.

As age-related inflammation is inhibitory to HF-SC function, ${ }^{26}$ the accumulation of senescent cells that secrete pro-inflammatory cytokines might also contribute to stem cell dysfunction in old tissues. Furthermore, as HF-SC are believed to be among the cells of origin for $\mathrm{SCC}^{54}$ their exposure to chronic inflammation originating from a senescent microenvironment might not only impede their function but also confer neoplastic growth.

Our findings expand our understanding of cancer development in the aged tissue, which is very pertinent to human 
a
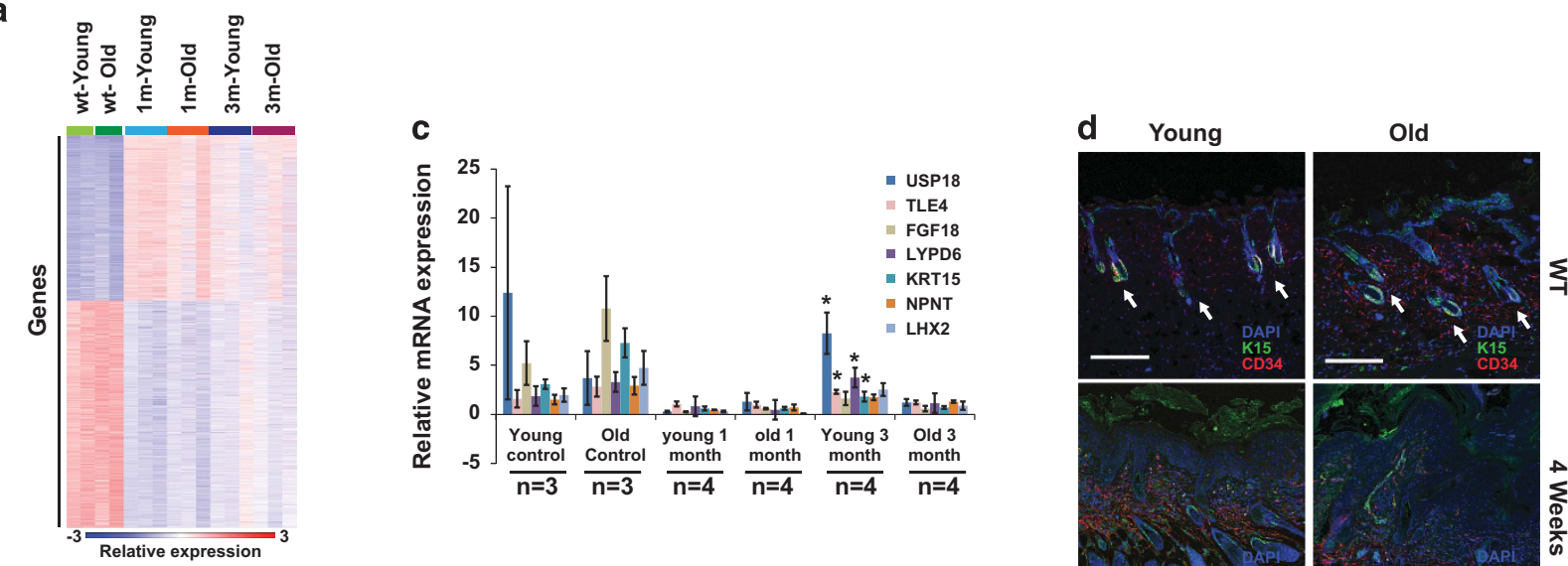

b
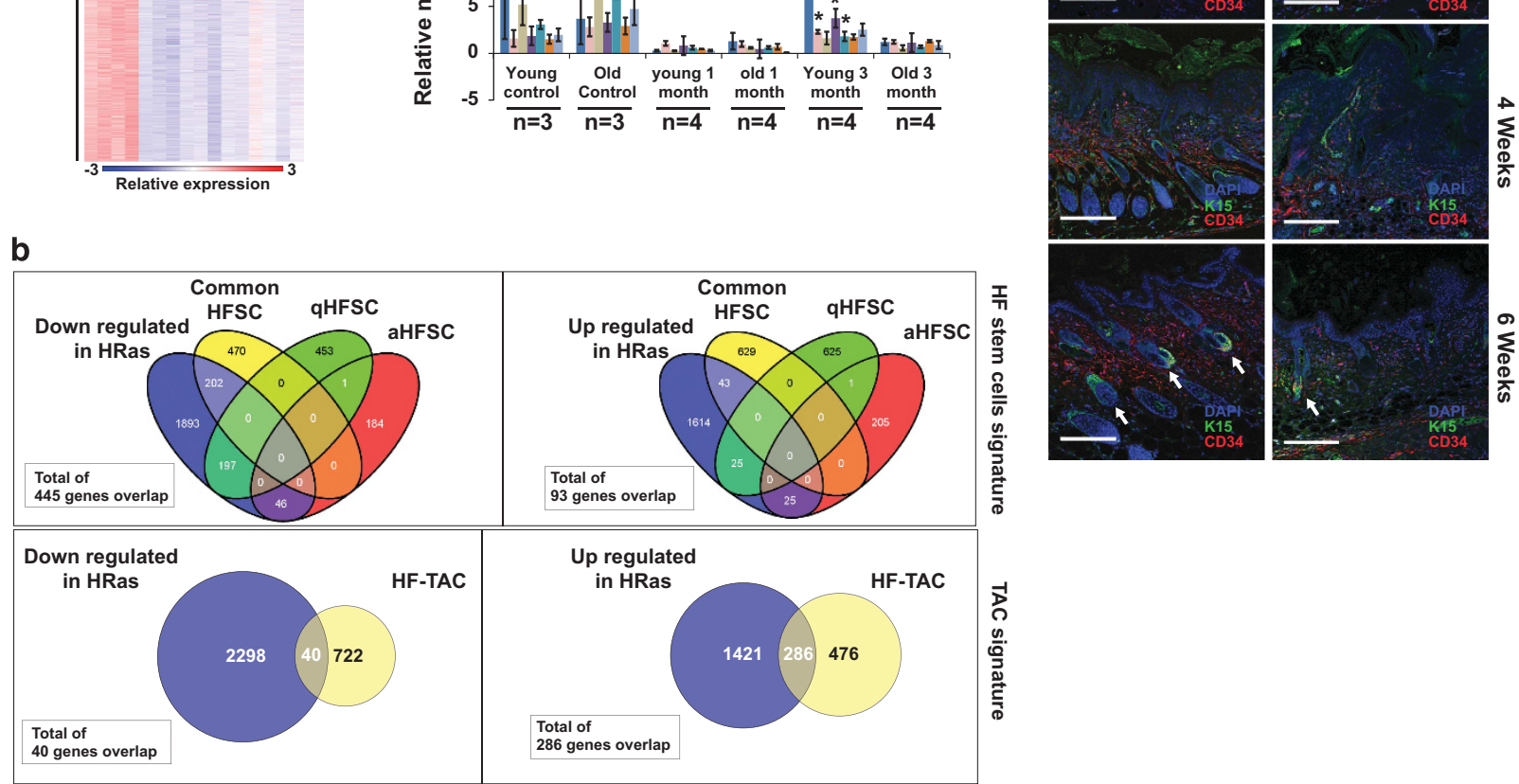

Figure 7 H-Ras activation downregulates many HF-SC-related genes. (a) Heat map of differential gene expression in the skin of WT and H-Ras transgenic young $(\mathrm{Y})$ and old (O) mice treated with 4-OHT for 1 or 3 months. Fold change $>1.5, P$-value (permutation test) $<0.05$. (b) Venn diagram showing the overlap between genes down- or upregulated in response to H-Ras activation, compared with previously defined HF-SC and TAC gene signatures. ${ }^{51}$ (c) qRT-PCR analysis of USP18, TLE4, FGF18, LYPD6, KRT15, NPNT and LHX2. Values represent relative expression normalized to Gapdh mRNA \pm SEM. $n=$ number of mice. ${ }^{*} P<0.05$. (d) Representative immunofluorescence images of back skin sections from WT and H-Ras-transgenic young and old mice treated with 4-OHT for 4 weeks (4 weeks) and after two additional weeks of 4-OHT withdrawal (6 weeks), stained for K15 (green), CD34 (red) and DAPI (blue). Scale bar $=20 \mu \mathrm{m}$

cancer. These findings suggest that aged malignant progression is associated with a conflicting inflammatory response, which on the one hand can facilitate tumor growth and invasion, whereas on the other hand suppressing tumor immune surveillance. Elaborating the dialog between tumor cells and the aged microenvironment might provide clues toward more efficient targeting of the processes that contribute to age-related malignancy.

\section{Materials and Methods}

Animals. All mouse experiments were approved by the institutional animal care and use committee (IACUC number 06021211-2) of the Weizmann Institute. 129S. $\mathrm{B} 6-\mathrm{Tg}(\mathrm{KRT} 14-\mathrm{Esr} 1 / \mathrm{H}-\mathrm{Ras}) 1 \mathrm{Pkha} / \mathrm{J}$ transgenic mice ${ }^{28}$ were purchased from Jackson Laboratories (Bar Harbor, ME, USA). 4-OHT (Sigma Aldrich Israel, Rehovot, Israel), dissolved in EtOH, was applied topically on the shaved back skin of transgenic mice, once a day, for 1 or 3 months.

Isolation of total RNA and qRT-PCR. Total RNA was isolated with NucleoSpin RNA II kit (Macherey-Nagel, Gmbh\&Co.KG, Düren, Germany). In all, $1.5 \mu \mathrm{g}$ aliquots of RNA were reverse transcribed using Moloney murine leukemia virus reverse transcriptase (Promega Corporation, Madison, WI, USA) and random hexamer primers (Amersham, GE Healthcare Bio-Sciences, Pittsburgh, PA, USA). RT-qPCR was performed using SYBR Green Master Mix (Applied Biosystems,
Foster City, CA, USA) in a StepOnePlus instrument (Applied Biosystems). A list of primers used in this study is provided in the Supplementary Material and methods.

Microarray hybridization and analysis. For expression microarray analysis, RNA was extracted as described above. In total, $1 \mu \mathrm{g}$ of RNA was used to prepare cDNA that was labeled and hybridized to Affymetrix GeneChip Mouse Gene 2.0 ST arrays. For analysis, the Affymetrix Console was used to normalize all arrays together using the robust multiarray average (RMA) algorithm. Differential gene expression was calculated using gene marker selection, Gene-E (Broad Institute). GSEA was performed using the GSEA tool. ${ }^{29,30}$

For histopathological analysis, immunohistochemistry and SA- $\beta$-gal staining see Supplementary materials and methods.

\section{Conflict of Interest}

The authors declare no conflict of interest.

Acknowledgements. This work was supported in part by a Center of Excellence grant (1779/11) from the Israel Science Foundation, Dr Miriam and Sheldon G Adelson Medical Research Foundation, the Robert Bosch Stiftung (Germany), the German-Israeli Foundation for Research and Development (GIF) and the MD Moross Institute for Cancer Research, by European Commission FP7 funding (INSPiRE agreement number 284460) and Aristeia II from GSRT, Greece. MO is incumbent of the Andre Lwoff chair in molecular biology. 
1. Campisi J. Aging, cellular senescence, and cancer. Ann Rev Physiol 2013; 75: 685-705.

2. Serrano M, Blasco MA. Cancer and ageing: convergent and divergent mechanisms. Nat Rev Mol Cell Biol 2007; 8: 715-722.

3. Malaguarnera G, Giordano M, Cappellani A, Berretta M, Malaguarnera M, Perrotta RE. Skin cancers in elderly patients. Anticancer Agents Med chem 2013; 13: 1406-1411.

4. Alam M, Ratner D. Cutaneous squamous-cell carcinoma. N Engl J Med 2001; 344: 975-983.

5. Swann JB, Smyth MJ. Immune surveillance of tumors. J Clin Invest 2007; 117: 1137-1146.

6. Girardi M, Oppenheim DE, Steele CR, Lewis JM, Glusac E, Filler R et al. Regulation of cutaneous malignancy by gammadelta T cells. Science 2001; 294: 605-609.

7. McElhaney JE, Effros RB. Immunosenescence: what does it mean to health outcomes in older adults? Curr Opin Immun 2009; 21: 418-424.

8. Finkel T, Serrano M, Blasco MA. The common biology of cancer and ageing. Nature 2007; 448: 767-774.

9. Fulop T, Larbi A, Witkowski JM, Kotb R, Hirokawa K, Pawelec G. Immunosenescence and cancer. Crit Rev Oncog 2013; 18: 489-513.

10. Montecino-Rodriguez E, Berent-Maoz B, Dorshkind K. Causes, consequences, and reversal of immune system aging. J Clin Invest 2013; 123: 958-965.

11. Lynch HE, Goldberg GL, Chidgey A, Van den Brink MR, Boyd R, Sempowski GD. Thymic involution and immune reconstitution. Trends Immunol 2009; 30: 366-373.

12. Rossi DJ, Bryder D, Zahn JM, Ahlenius H, Sonu R, Wagers AJ et al. Cell intrinsic alterations underlie hematopoietic stem cell aging. Proc Natl Acad Sci USA 2005; 102: 9194-9199.

13. Pang WW, Price EA, Sahoo D, Beerman I, Maloney WJ, Rossi DJ et al. Human bone marrow hematopoietic stem cells are increased in frequency and myeloid-biased with age. Proc Natl Acad Sci USA 2011; 108: 20012-20017.

14. Maue AC, Yager EJ, Swain SL, Woodland DL, Blackman MA, Haynes L. T-cell immunosenescence: lessons learned from mouse models of aging. Trends Immunol 2009; 30: 301-305.

15. Chou JP, Effros RB. T cell replicative senescence in human aging. Curr Pharm Des 2013; 19: $1680-1698$.

16. Effros RB. Loss of CD28 expression on T lymphocytes: a marker of replicative senescence. Dev Comp Immunol 1997; 21: 471-478.

17. Montes CL, Chapoval Al, Nelson J, Orhue V, Zhang X, Schulze DH et al. Tumor-induced senescent $T$ cells with suppressor function: a potential form of tumor immune evasion. Cancer Res 2008; 68: 870-879.

18. Grivennikov SI, Greten FR, Karin M. Immunity, inflammation, and cancer. Cell 2010; 140: 883-899.

19. Ben-Neriah $\mathrm{Y}$, Karin M. Inflammation meets cancer, with NF-kappaB as the matchmaker. Nat Immunol 2011; 12: 715-723.

20. El-Serag HB, Rudolph KL. Hepatocellular carcinoma: epidemiology and molecular carcinogenesis. Gastroenterology 2007; 132: 2557-2576.

21. Hu B, Castillo E, Harewood L, Ostano P, Reymond A, Dummer R et al. Multifocal epithelial tumors and field cancerization from loss of mesenchymal CSL signaling. Cell 2012; 149 1207-1220.

22. Hanahan D, Weinberg RA. Hallmarks of cancer: the next generation. Cell 2011; 144 646-674.

23. Franceschi C, Bonafe M, Valensin S, Olivieri F, De Luca M, Ottaviani E et al. Inflamm-aging. An evolutionary perspective on immunosenescence. Ann N Y Acad Sci 2000; 908: 244-254

24. Sikora E, Bielak-Zmijewska A, Mosieniak G. Cellular senescence in ageing, age-related disease and longevity. Curr Vasc Pharmacol 2013; 12: 698-706.

25. Coppe JP, Desprez PY, Krtolica A, Campisi J. The senescence-associated secretory phenotype: the dark side of tumor suppression. Annu Rev Pathol 2010; 5: 99-118.

26. Doles J, Storer M, Cozzuto L, Roma G, Keyes WM. Age-associated inflammation inhibits epidermal stem cell function. Genes Dev 2012; 26: 2144-2153.

27. Blanpain C. Tracing the cellular origin of cancer. Nat Cell Biol 2013; 15: 126-134.

28. Tarutani M, Cai T, Dajee M, Khavari PA. Inducible activation of Ras and Raf in adult epidermis. Cancer Res 2003; 63: 319-323.

29. Subramanian A, Tamayo P, Mootha VK, Mukherjee S, Ebert BL, Gillette MA et al. Gene set enrichment analysis: a knowledge-based approach for interpreting genome-wide expression profiles. Proc Natl Acad Sci USA 2005; 102: 15545-15550.

30. Mootha VK, Lindgren CM, Eriksson KF, Subramanian A, Sihag S, Lehar J et al. PGC-1alpharesponsive genes involved in oxidative phosphorylation are coordinately downregulated in human diabetes. Nat Genet 2003; 34: 267-273.

31. Hummerich L, Muller R, Hess J, Kokocinski F, Hahn M, Furstenberger G et al. Identification of novel tumour-associated genes differentially expressed in the process of squamous cell cancer development. Oncogene 2006; 25: 111-121.

32. Serrano M, Lin AW, McCurrach ME, Beach D, Lowe SW. Oncogenic ras provokes premature cell senescence associated with accumulation of p53 and p16INK4a. Cell 1997; 88: 593-602.

33. Halazonetis TD, Gorgoulis VG, Bartek J. An oncogene-induced DNA damage model for cancer development. Science 2008; 319: 1352-1355.

34. Krtolica A, Parrinello S, Lockett S, Desprez PY, Campisi J. Senescent fibroblasts promote epithelial cell growth and tumorigenesis: a link between cancer and aging. Proc Natl Acad Sci USA 2001; 98: 12072-12077.

35. Tremain R, Marko M, Kinnimulki V, Ueno H, Bottinger E, Glick A. Defects in TGF-beta signaling overcome senescence of mouse keratinocytes expressing v-Ha-ras. Oncogene 2000; 19: 1698-1709.
36. Coppe JP, Patil CK, Rodier F, Sun Y, Munoz DP, Goldstein J et al. Senescence-associated secretory phenotypes reveal cell-nonautonomous functions of oncogenic RAS and the p53 tumor suppressor. PLoS Biol 2008; 6: 2853-2868.

37. Kansara M, Leong HS, Lin DM, Popkiss S, Pang P, Garsed DW et al. Immune response to RB1-regulated senescence limits radiation-induced osteosarcoma formation. J Clin Invest 2013; 123: 5351-5360

38. Weng H, Deng Y, Xie Y, Liu H, Gong F. Expression and significance of HMGB1, TLR4 and NF-kappaB p65 in human epidermal tumors. BMC Cancer 2013; 13: 311.

39. Mittal D, Saccheri F, Venereau E, Pusterla T, Bianchi ME, Rescigno M. TLR4-mediated skin carcinogenesis is dependent on immune and radioresistant cells. EMBO J 2010; 29: 2242-2252.

40. Laouini D, Alenius H, Bryce P, Oettgen H, Tsitsikov E, Geha RS. IL-10 is critical for Th2 responses in a murine model of allergic dermatitis. J Clin Invest 2003; 112: 1058-1066.

41. Choi JP, Kim YS, Kim OY, Kim YM, Jeon SG, Roh TY et al. TNF-alpha is a key mediator in the development of Th2 cell response to inhaled allergens induced by a viral PAMP doublestranded RNA. Allergy 2012; 67: 1138-1148.

42. Kim BE, Leung DY, Boguniewicz M, Howell MD. Loricrin and involucrin expression is downregulated by Th2 cytokines through STAT-6. Clin Immunol 2008; 126: 332-337.

43. Howell MD, Fairchild HR, Kim BE, Bin L, Boguniewicz M, Redzic JS et al. Th2 cytokines act on S100/A11 to downregulate keratinocyte differentiation. J Invest Dermatol 2008; 128: 2248-2258.

44. Shurin MR, Lu L, Kalinski P, Stewart-Akers AM, Lotze MT. Th1/Th2 balance in cancer, transplantation and pregnancy. Springer Semin Immunopathol 1999; 21: 339-359.

45. Bosco A, McKenna KL, Devitt CJ, Firth MJ, Sly PD, Holt PG. Identification of novel Th2associated genes in T memory responses to allergens. J Immunol 2006; 176: 4766-4777.

46. Martinez FO, Gordon S, Locati M, Mantovani A. Transcriptional profiling of the human monocyte-to-macrophage differentiation and polarization: new molecules and patterns of gene expression. J Immunol 2006; 177: 7303-7311.

47. Pardoll DM. The blockade of immune checkpoints in cancer immunotherapy. Nat Rev Cancer 2012; 12: 252-264.

48. Belai EB, de Oliveira CE, Gasparoto TH, Ramos RN, Torres SA, Garlet GP et al. PD-1 blockage delays murine squamous cell carcinoma development. Carcinogenesis 2014; 35: 424-431.

49. Krizhanovsky V, Yon M, Dickins RA, Hearn S, Simon J, Miething $C$ et al. Senescence of activated stellate cells limits liver fibrosis. Cell 2008; 134: 657-667.

50. Kang TW, Yevsa T, Woller N, Hoenicke L, Wuestefeld T, Dauch D et al. Senescence surveillance of pre-malignant hepatocytes limits liver cancer development. Nature 2011; 479: 547-551.

51. Lien WH, Guo X, Polak L, Lawton LN, Young RA, Zheng D et al. Genome-wide maps of histone modifications unwind in vivo chromatin states of the hair follicle lineage. Cell Stem Cell 2011; 9: 219-232

52. Cotsarelis G. Epithelial stem cells: a folliculocentric view. J Invest Dermatol 2006; 126 : 1459-1468.

53. Quintanilla M, Brown K, Ramsden M, Balmain A. Carcinogen-specific mutation and amplification of Ha-ras during mouse skin carcinogenesis. Nature 1986; 322: 78-80.

54. Lapouge G, Youssef KK, Vokaer B, Achouri Y, Michaux C, Sotiropoulou PA et al. Identifying the cellular origin of squamous skin tumors. Pro Natl Acad Sci USA 2011; 108: 7431-7436.

55. Ren ZP, Ahmadian A, Ponten F, Nister M, Berg C, Lundeberg J et al. Benign clonal keratinocyte patches with $p 53$ mutations show no genetic link to synchronous squamous cell precancer or cancer in human skin. Am J Pathol 1997; 150: 1791-1803.

56. Butani AK, Arbesfeld DM, Schwartz RA. Premalignant and early squamous cell carcinoma. Clin Plast Surg 2005; 32: 223-235.

57. Spencer JM, Kahn SM, Jiang W, DeLeo VA, Weinstein IB. Activated ras genes occur in human actinic keratoses, premalignant precursors to squamous cell carcinomas. Arch Dermatol 1995; 131: 796-800.

58. de Visser KE, Korets LV, Coussens LM. De novo carcinogenesis promoted by chronic inflammation is B lymphocyte dependent. Cancer Cell 2005; 7: 411-423.

59. Briso EM, Guinea-Viniegra J, Bakiri L, Rogon Z, Petzelbauer P, Eils R et al. Inflammationmediated skin tumorigenesis induced by epidermal c-Fos. Genes Dev 2013; 27: 1959-1973.

60. Wilson ML, Elston DM, Tyler WB, Marks VJ, Ferringer T. Dense lymphocytic infiltrates associated with non-melanoma skin cancer in patients with chronic lymphocytic leukemia. Dermatol Online J 2010; 16: 4.

61. Di Piazza M, Nowell CS, Koch U, Durham AD, Radtke F. Loss of cutaneous TSLPdependent immune responses skews the balance of inflammation from tumor protective to tumor promoting. Cancer Cell 2012; 22: 479-493

62. Mansfield AS, Nevala WK, Dronca RS, Leontovich AA, Shuster L, Markovic SN. Normal ageing is associated with an increase in Th2 cells, MCP-1 (CCL1) and RANTES (CCL5), with differences in SCD40L and PDGF-AA between sexes. Clin Exp Immunol 2012; 170: 186-193.

63. Mirza N, Pollock K, Hoelzinger DB, Dominguez AL, Lustgarten J. Comparative kinetic analyses of gene profiles of naive CD4+ and CD8+T cells from young and old animals reveal novel age-related alterations. Aging Cell 2011; 10: 853-867.

64. de Souza Jr DA, Toso VD, Campos MR, Lara VS, Oliver C, Jamur MC. Expression of mast cell proteases correlates with mast cell maturation and angiogenesis during tumor progression. PloS One 2012; 7: e40790. 
65. Ch'ng S, Wallis RA, Yuan L, Davis PF, Tan ST. Mast cells and cutaneous malignancies. Mod Pathol 2006; 19: 149-159.

66. Siebenhaar F, Metz M, Maurer M. Mast cells protect from skin tumor development and limit tumor growth during cutaneous de novo carcinogenesis in a Kit-dependent mouse model. Exp Dermatol 2014; 23: 159-164.

67. Biswas SK, Allavena P, Mantovani A. Tumor-associated macrophages: functional diversity, clinical significance, and open questions. Semin Immunopathol 2013; 35: 585-600.

68. Freije A, Ceballos L, Coisy M, Barnes L, Rosa M, De Diego E et al. Cyclin E drives human keratinocyte growth into differentiation. Oncogene 2012; 31: 5180-5192.

69. Tokarsky-Amiel R, Azazmeh N, Helman A, Stein Y, Hassan A, Maly A et al. Dynamics of senescent cell formation and retention revealed by p14ARF induction in the epidermis. Cancer Res 2013; 73: 2829-2839.
70. Vallejo AN, Weyand CM, Goronzy JJ. T-cell senescence: a culprit of immune abnormalities in chronic inflammation and persistent infection. Trends Mol Med 2004; 10: 119-124.

71. Meloni F, Morosini M, Solari N, Passadore I, Nascimbene C, Novo M et al. Foxp3 expressing CD4+ CD25+ and CD8+CD28-T regulatory cells in the peripheral blood of patients with lung cancer and pleural mesothelioma. Hum Immunol 2006; 67: 1-12.

72. Ye SW, Wang Y, Valmori D, Ayyoub M, Han Y, Xu XL et al. Ex-vivo analysis of CD8+ T cells infiltrating colorectal tumors identifies a major effector-memory subset with low perforin content. J Clin Immunol 2006; 26: 447-456.

73. Effros RB. The role of CD8 T cell replicative senescence in human aging. Discov Med 2005; 5: $293-297$.

74. Sagiv A, Biran A, Yon M, Simon J, Lowe SW, Krizhanovsky V. Granule exocytosis mediates immune surveillance of senescent cells. Oncogene 2013; 32: 1971-1977.

Supplementary Information accompanies this paper on Cell Death and Differentiation website (http://www.nature.com/cdd) 